\title{
Four-Quadrant Bi-Directional DC Drive System based on PWM Technique using SG3524 for Chopper (DC-DC) Converter
}

\author{
D. K. Shah* (D.A.Doshi) \\ Dept. of Electronics Engg., P.R.E.C. Loni, India \\ Accepted 14 April 2016, Available online 15 April 2016, Vol.6, No.2 (April 2016)
}

\begin{abstract}
The goal of this work is to control the speed of the PMDC motor. Also the motor can be control in both the directions i.e. forward as well as reverse direction along with regenerative braking.The specialty is that the power circuit is made up of international rectifier IGBT IRG4BC20S which have low operating frequency upto $1 \mathrm{KHz}$. It consists of completely innovative logic circuitry which uses Pulse Width Modulation, for producing control pulses of variable width, and a Direction Changing Logic technique for rotating of motor in both directions also it doesn't involve any triggering circuit. The class E chopper circuit is used for four quadrant bi directional operation.
\end{abstract}

Keywords: PMDC motor, Speed control, PWM (SG3524) as controller, $4 Q$ class E chopper

\section{Introduction}

Speed control of PMDC motor could be achieved by using manually done mechanical and in the form of voltage and current i.e electrical ones. In past, speed controls of drives are difficult and required immensely extremely large size hardware to implement. Thus the development has generated these drives back to position of formidable pertinence which give elevate to A.C drives. Some almost used in mills such as rolling, paper , traction, printing, textiles etc. Fractional horse power D.C drives are widely used. (Gopal K. Dubey,et al ,1989 ). Due to the facility of supplying constantly variable dc voltage from a.c to d.c convertor or d.c to d.c convetor had made a revolution in modern industrial equipment and variable drives (Muhammad Rasid et al, 2003). Adjustable speed drives are operated over a large range, by controlling armature voltage or field excitation voltage(Atul Dewangan, Nibbedita, Sashi,Vinod Yadu et al, 2012).

The invention of power semiconductors devices make the advantage of the D.C drive system for the changeable speed condition. Based on the benefit of uncomplicated construction and easy of control of the drive, this technology can be taken for the future development.

MOSFET, BJT , SCR and GTO along with various analog and digital chips used in triggering and power circuits have made DC drives system more accessible for control in numbers of applications. But, recent development in the area of semiconductors technology have generated a new power device for variable

${ }^{*}$ Corresponding author: D. K. Shah frequency drives as MOSFET, IGBT. The use of IGBT in chopper circuit for the control and rotation of the motor in clockwise and counter clockwise direction i.e forward and reverse direction. The main objective of this work is to become familiar with design (Ms. D. K. Shah et al, 2013).

\section{Related Works}

A number of scholars works have been found in the literature regarding the solid state power devices for the control of DC drives. Alexendra Mora elucidate in his paper the use of chopper in half bridge configuration. Due to half bridge configuration the DC motor rotate only in forward direction (Alexandru Morar et al, (2006). Axelrod B. have shown 4Q bidirectional drive system for controlling of DC motor based on PWM dc-dc converter using SPICE simulation software. There converter offers both motoring and regenerative braking mode of operation (Axelrod, B. et $a l, 2008)$. Paul A.R and George M. in his paper shows digital pulse width modulation control techniques for trapezoidal brushless D C motor drives. This digital control treats BLDC motor as a digital system and regulation the speed of the motor (Paul, A.R. et al,2011). Saunders with his collogues have shown in their paper how PWM techniques is useful for motor drive applications. Also they shows IGBT drives have faster output voltage rise time than other power drives (Saunders, Skibiniks, EVon, Kempkes et al,1996). Eric R. Motto, from Powerex Inc., Youngwood, Pennsylvania, USA shows in his paper shows the design and implementation of the necessary gate driver circuit, along with protection for IGBT devices 
(Eric R. Motto). VAN Dijk E, Sruijt J N, O'sullivan D M, Klaassens J B, shows in there paper about PWM switching modeling. They shows the simple method for modeling PWM DC to DC converter operating in the continuous conduction mode. The main advantage of PWM method is its versatility and simple implementations compared to other methods. The basics idea is the replacement of the switches in the converter by their time averaging models. (VAN Dijk E, Sruijt J N, O'sullivan D M, Klaassens J B et al, 1995)

In this paper by considering all the literature I have made the system which control the speed of PMDC motor in the all operating modes using PWM technique.

\section{Methodology}
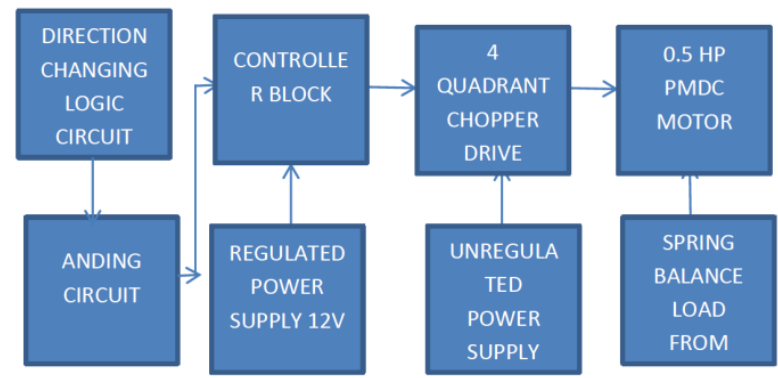

Fig 1 Block Diagram

As the system is predicated on speed control of PMDC motor, so the system is built with speed control and direction of revolving at constant load condition. That signifies motor will run at variable speed at constant load condition. In implementing this work frequency independent PWM output with variable obligation cycle from $0 \%$ to $100 \%$ is engendered. Furthermore a direction change logic circuit is fabricated for the transmuting the direction of motor (forward and reverse). Withal there is utilization of soft start circuit, to safe the motor from inrush current which may cause damage .

The PMDC motor to be controlled is supplied by DC source through a 4 quadrant class $E$ chopper circuit. The output D.C voltage obtained from chopper is fed to the PMDC motor which rotate the motor in clockwise and counter clockwise direction according to the conduction of chopper IGBT pair. With the avail of speed measuring meter (tachometer) the speed of motor is measured in Rotation per minute (RMP)..

\subsection{Circuit Description}

\subsubsection{Controller Block}

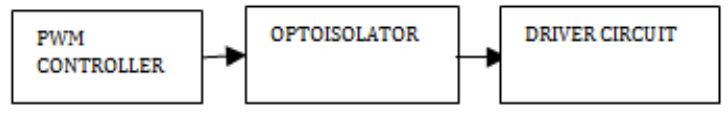

Fig 2 Block diagram of controller block
Main blocks used are pulse width modulator, optoisolator and driver circuit. The speed is controlled by the variable potentiometer, which decided the D.C. level input to PWM controller. The pulse width gets modulated according to the D.C. level. PWM is achieved using SG 3524. The output of PWM controller is fed to the opto-isolators, which are required for the isolation of the IGBT in bridge configuration. The output of the opto-isolator is given to the driver for respective IGBT's.

\subsubsection{Regulating PWM Controller (SG 3524)}

PWM is Pulse generator is a main part of the project which is SG3524 or SG 3524. It will generate the PWM output. The input to the PWM is positive d.c. voltage which is used to decided the DC level I/P to PWM . By adjusting the register valve the duty cycle can be controlled. When motor run at $10 \%$ duty cycle the output voltage develop across chopper is very small which in turn makes the speed of motor to be less but for $80 \%$ duty cycle the speed of motor get increased as the voltage across the chopper is more. This increase or decreased in speed is sensed by tachometer. But if any load occurs, the speed of motor get decreased for the same duty cycle with increased in current. Also, the direction of PMDC motor can be change with the help of J-K flip flop in the direction change logic circuit. If the motor rotate in clockwise direction then after switching other pair of switches the motor will rotate in anticlockwise direction. The control of the armature voltage is done with the help of IGBT power circuit Due to the IGBT power circuit the motor is rotated in both the direction. Diodes across the IGBT $S$ are used for freewheeling purposes.

The freewheeling diode along with one IGBT from one pair get turn on for having clockwise and anticlockwise regenerative breaking mode..

The 0/P of PWM controller is fed to the optoisolator which is required for the isolation of the IGBT in bridge configuration. The $\mathrm{o} / \mathrm{p}$ of the opto-isolator is given to the driver for respective IGBT.

\subsection{Gate Driver Circuit}

Gate driver circuit is the circuit which is used to drive the gate operated power devices such as SCR, MOSFET, IGBT. It consist of opto-couplers. With the advantage of isolation optoisolator isolates the signal from the driver circuit to power circuit. Here MCT2E opto coupler is used.

\section{Result \& Discussion}

The obtained results are given below

\section{Four Quadrant Class E Chopper circuit output}

From PWM a fixed frequency square wave pulse is generated of $12 \mathrm{v}$ is fed to IGBT based chopper circuit. The obtained output voltageV0(dc) of class E chopper 
is given to the inductive load as DC motor. According to the gating pulse, IGBT pair gets operated such as pair G1-G2 is used for clockwise operation while G3-G4 used for the counter clockwise direction. Due the conduction of IGBT pair the motor will start rotating in clockwise and anticlockwise direction. In each pair IGBT freewheeling diode is used the use of diode for back emf protection.

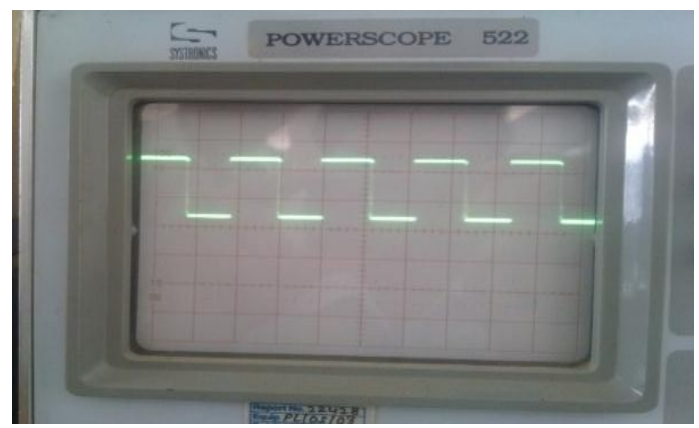

Fig 3 PWM output at Mid pot position (50\% duty cycle)

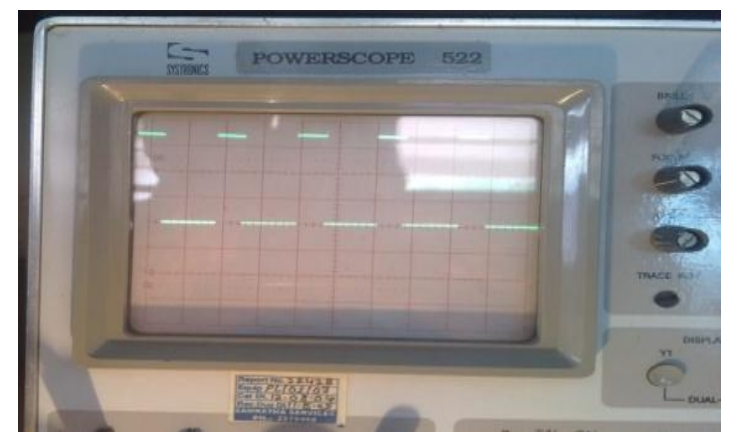

Fig 4 Chopper Output (Forward Motoring)

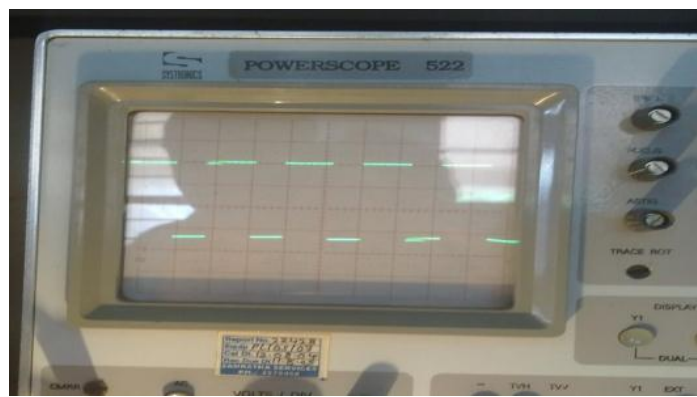

FIG 5 Chopper Output (Reverse Motoring)

Table 1 Forward motoring mode

\begin{tabular}{|c|c|c|}
\hline $\begin{array}{c}\text { Current in } \\
\text { amperes }\end{array}$ & Voltage in volts & $\begin{array}{c}\text { Speed in } \\
\text { rpm }\end{array}$ \\
\hline 0.15 & 20 & 179 \\
\hline 0.16 & 40 & 326 \\
\hline 0.2 & 60 & 472 \\
\hline 0.3 & 80 & 648 \\
\hline 0.35 & 100 & 882 \\
\hline 0.4 & 120 & 1050 \\
\hline 0.42 & 130 & 1176 \\
\hline 0.45 & 150 & 1307 \\
\hline 0.45 & 160 & 1422 \\
\hline
\end{tabular}

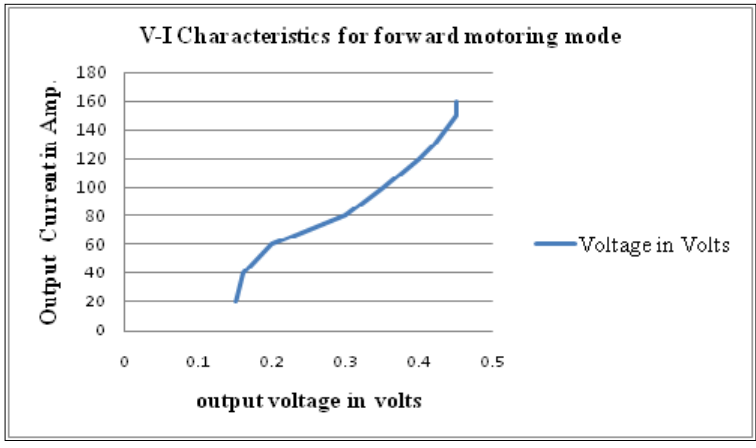

Table 2 Reverse Motoring Mode

\begin{tabular}{|c|c|c|}
\hline $\begin{array}{c}\text { Current in } \\
\text { ampere }\end{array}$ & Voltage in volts & Speed in rpm \\
\hline-0.1 & -20 & 139 \\
\hline-0.15 & -40 & 328 \\
\hline-0.2 & -60 & 439 \\
\hline-0.22 & -80 & 566 \\
\hline-0.25 & -100 & 751 \\
\hline-0.3 & -120 & 878 \\
\hline-0.35 & -130 & 1037 \\
\hline-0.4 & -150 & 1200 \\
\hline-0.4 & -160 & 1340 \\
\hline
\end{tabular}

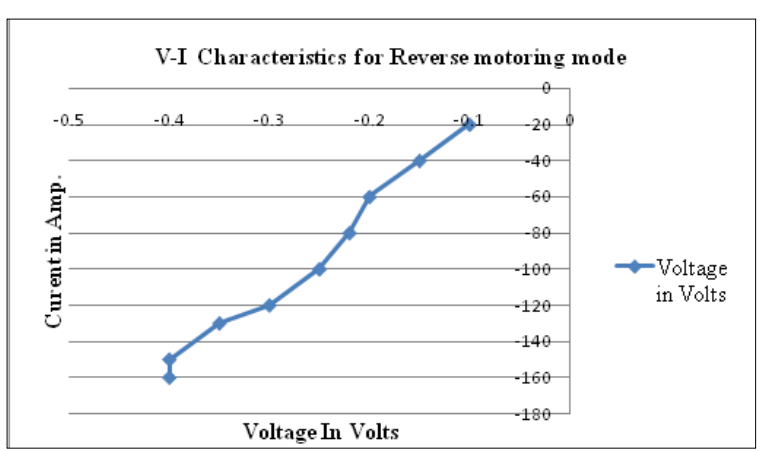

Table 3 Four Quadrant Chopper Operation_Forward Motoring Mode

\begin{tabular}{|c|c|}
\hline Current in Ampere & Voltage in Volts \\
\hline 0.15 & 20 \\
\hline 0.16 & 40 \\
\hline 0.2 & 60 \\
\hline 0.3 & 80 \\
\hline 0.35 & 100 \\
\hline 0.4 & 120 \\
\hline 0.42 & 130 \\
\hline 0.45 & 150 \\
\hline 0.45 & 160 \\
\hline-0.02 & 20 \\
\hline-0.1 & -20 \\
\hline-0.15 & -40 \\
\hline-0.2 & -60 \\
\hline-0.22 & -80 \\
\hline-0.25 & -100 \\
\hline-0.3 & -120 \\
\hline-0.35 & -130 \\
\hline-0.4 & -150 \\
\hline-0.4 & -160 \\
\hline 0.06 & -20 \\
\hline
\end{tabular}




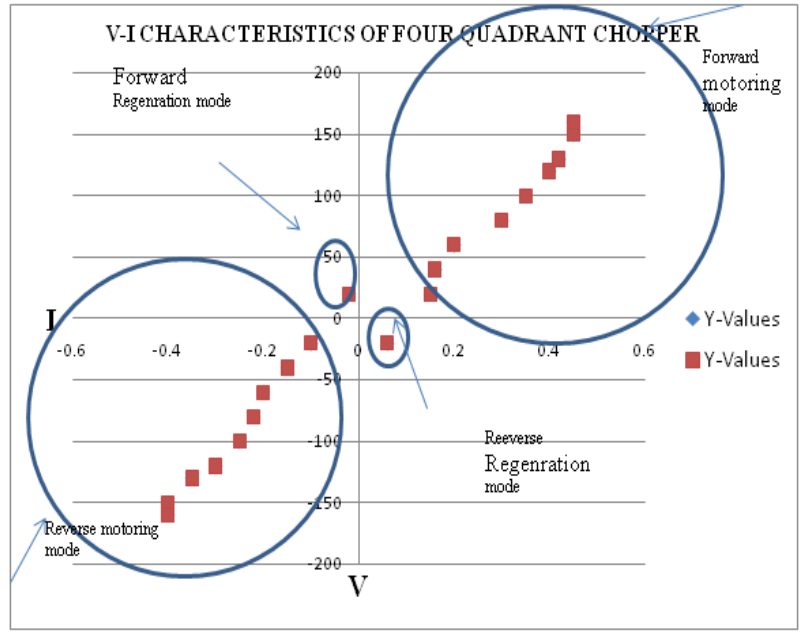

\section{Conclusion}

By using this technique the speed of motor get controlled using PWM technique with class E chopper. The proposed system is open loop i.e there is no used of feedback. Due the use of open loop the circuit become simple, size get reduced. Also it become cheaper \& more robust. .

\section{Acknowledgments}

Firstly, I would like to pay respectfully thanks to authors, teachers and admirer supervisors. Special thanks to my colleagues S.S.Lavhate, R. S. Jhaghirdar Principal of PREC, Loni for encouragement.

\section{References}

Dipti K. Shah , B. T. Deshmukh (2015), PMDC motor control using PWM techniques, Narosa publishing House New Delhi, pp 474-476.

D. K. Shah (2013), Speed control of PMDC motor using LM3524 PWM Ic International Journal of Computer Technology and Electronics Engineering (IJCTEE)Volume 3,pp-57-59
Dipti K. Shah , B. T. Deshmuk (2012), DC drive system using igbt chopper circuit, Proceeding In International Conference At Deogiri College Of Engg. Aurangabad.

Dipti K. Shah , B. T. Deshmukh (2012), Dc To D,C Chopper Fed IGBT Power Circuit Publish In International journal of engineering and research applications (Ijera), Vol.2, Issue2, Mar-Apr2012, Pp.220-222

Dipti K. Shah , B. T. Deshmukh (2012), Reversible D.C.Drives Using 4 Q IGBt Chopper Circuit For Industrial Application, Publish In International Journal Of Electrical Engineering \& Technology (Ijeet), Vol3, Issue 1, Pp-282-287

Gopal K. Dubey,(1989),Fundamentals of Electric Derives, Narosa publishing House New Delhi,

Muhammad Rasid (2003), Power Electronics circuits, Devices and Application, Prentice Hall, $3^{\text {rd }}$ edition.

Atul Dewangan, Nibbedita, Sashi,Vinod Yadu(2012),PWM Based Automatic closed loop speed Of DC motor, International Journal of Engineering Trends And Technology- volume 3 issue2.pp-210-212

Alexandru Morar9(2006), Dc Drive System With The Insulated Gate Bipolar Transistors, By Petru Maior University of Tg. - Mures, Faculty Of Engineering 1, Nicolae Iorga Str, IEEE, .pp-265-270

Axelrod, B.(2008), Four-quadrant bi-directional drive system based on PWM DC-DC converter Advanced Motion Control, 2008. AMC '08. 10th IEEE International Workshop, Pp: 377 $-381$

Paul, A.R. (2011), Brushless DC motor control using digital PWM techniques, Signal Processing, Communication, Computing and Networking Technologies (ICSCCN), 2011 International Conference, Pp 733 - 738

Saunders, Skibiniks, EVon, Kempkes (1996), Riding the Reflected wave- IGBT Drive Technology Demands New Motor and cable considerations, IEEE IAS- Petroleum \& Chemical Industry Conference, Philadelphia ,sept.-23-25, 1996, pp -75-84.

International Rectifier, data catalog( IGBT)

www.national.com (Regulator IC, IC 555, MTC2E)

Eric R. Motto, Hybrid Circuits Simplify IGBT Module Gate Drive, Powerex Inc., Youngwood, Pennsylvania, USA

VAN Dijk E, Sruijt J N, O'sullivan D M, Klaassens J B (1995) ,PWM -switching modeling of dc -dc converter Power Electronics, IEEE Transactions on by, Volume 10, Issues, Pp 659-665

http://www.st.com/web/en/resource/technical/document/ datasheet/CD00000117.pdf ( SG3524) 